\title{
HISTÓRIA FEMINISTA, GENEALOGÍAS QUEER ${ }^{1}$
}

\section{Re $/$ ista Trans ersos}

Pablo Pérez Navarro

Universidade de Coimbra

pabloperez@ces.uc.pt

\section{Resumo:}

Não existe uma trajetória histórica capaz de explicar, por si só, o surgimento de teorias queer no início dos anos noventa. Suas possíveis genealogias se estendem em múltiplas direções, dentro e fora dos limites da filosofia pós-estruturalista, dos estudos gays e lésbicos e, é claro, dos muros da academia. Apesar desta certeza, este artigo oferece uma genealogia, entre muitas possíveis, da crítica queer como um processo de fragmentação e proliferação de lutas e posições subjetivas, nas margens da política de identidade enraizada na história do pensamento e das políticas feministas.

Palavras-chave: teoria queer; pensamento feminista; identidade; sujeição.

\begin{abstract}
:
There is no one single historical trajectory that can explain, by itself, the emergence of queer theories at the beginnig of the nineties. Possible genealogies extend in multiple directions, within and outside the limits of poststructuralism, gay and lesbian studies and, of course, of the academy. Notwithstanding, this paper offers a genealogy, among others, of queer criticism as a process of fragmentation and proliferation of struggles and subjective possitions at the margins of identity politics, rooted in the history of feminist politics and scholarship.
\end{abstract}

Keywords: queer theories; feminist thinking; identity; subjection.

El relato de los orígenes es una estrategia dentro de una narración que, al explicar una única historia autorizada sobre un pasado que ya no se puede recuperar, hace surgir la constitución de la ley como una inevitabilidad histórica.

Judith Butler

There is no space from which the sexed subaltern subject can speak.

Gayatri Chakravorty Spivak

\section{Introdução}

Le deuxieme sexe, de Simone de Beauvoir (1949), é frequentemente citado como o texto inaugural da filosofia feminista contemporânea. Da mesma forma, não é rara a referência a Gender Trouble de Judith Butler (2002), publicado em 1990, como a origem da teoria ou dos

\footnotetext{
${ }^{1}$ Este ensaio foi desenvolvido no âmbito do projeto INTIMATE - Cidadania, Cuidado e Escolha: A Micropolítica da Intimidade na Europa do Sul, financiado pelo European Research Council através do seu $7^{\circ}$ programa-quadro (FP/2007-2013)/ERC Grant Agreement [338452].
} 
estudos queer. Sem dúvida, ambos trabalhos representam acontecimentos de grande magnitude, devido à profundidade das provocações que eles produziram e continuam a produzir nos campos discursivos em que brotaram como para merecer tais considerações. Nesse sentido, pelo menos, caberia na figura da poeta vigorosa a qual se referiria o neopragmatista Richard Rorty:

Bem, embora as poetas vigorosas [strong poets; o feminino universal é meu] são, como todos os outros animais, produtos causais das forças naturais, são produtos capazes de contar a história de sua própria produção com palavras que nunca foram usadas. A linha que separa a fraqueza da força é, portanto, a linha que separa o uso de uma linguagem familiar e universal da produção de uma linguagem que, embora inicialmente incomum e idiossincrática, de alguma forma torna tangível a cega marca que toda a nossa ação carrega. Com sorte - esse tipo de sorte em que reside a diferença existente entre gênio e excentricidade - na geração seguinte essa linguagem lhe parecerá inevitável. Suas ações terão essa marca. (RORTY, 1991: p. 49; tradução minha).

Trata-se, portanto, desse tipo de teoria capaz de produzir todo um novo vocabulário para renovar não apenas as questões que seus antecessores enfrentavam, mas o exército de metáforas, segundo a formulação de Nietzsche, com o qual respondê-las. Esse é o tipo de profundidade, a do acontecimento, que força comentaristas posteriores a indicar certas publicações como momentos inaugurais, origens de diferentes correntes de pensamento, como as sucessivas "ondas feministas" ou, ocasionalmente, a abertura de um campo de interrogação crítico em busca de um novo nome, como aconteceu com os estudos queer.

Tais metáforas são, em geral, úteis quando se trata de produzir um mapa da história de qualquer campo teórico. No entanto, como o próprio tratamento dado por Rorty à categoria da poeta vigorosa, não deixam de ter o efeito problemático de esconder, pelo menos até certo ponto, que os "novos" vocabulários precisam estar suficientemente imersos nos campos discursivos que os precedem para poderem assim transformá-los. Nesse sentido, apontam para novos rumos do pensamento crítico, sem soltar as amarras de seu próprio pertencimento ou, em outras palavras, sem renunciar ao ar de família, como diria Wittgenstein, com os discursos com os quais se relacionam mais estreitamente. Nem Butler nem Beauvoir inauguram, no sentido pleno, um novo jogo de linguagem. Em vez disso, forçaram os limites discursivos das escolas filosóficas que mais diretamente se relacionavam com cada uma delas e, ao mesmo tempo, os da teoria feminista de suas predecessoras. Assim, mais do que a diferença entre vocabulários 
"novos" e "velhos", trata-se do exercício da escrita nas margens, da contaminação dos discursos, de um atrito na superfície do contato entre diferentes tradições do pensamento. Em outras palavras, o que Butler chamaria de um exercício de "tradução cultural" (2002, ix): onde Butler o praticou entre o pós-estruturalismo e a teoria feminista, Beauvoir o teria feito quatro décadas antes, entre o existencialismo e a própria teoria feminista.

A seguir, mais do que os novos vocabulários têm de emergentes, pretendo explorar (algumas) continuidades que ligam entre si diferentes episódios da teoria feminista e, muito especificamente, aqueles que, ao meu entender, mais diretamente conduzem ao surgimento das teorias queer. Não para negar a profundidade de eventos como os aqui citados, no que eles têm de reconfiguração radical da paisagem teórica do feminismo, mas para expor, ainda que timidamente, algumas das pontes que nos permitem entender o modo pelo qual os exercícios de tradução cultural respondem, de fato, aos desafios teóricos e políticos abertos no discurso feminista. Tal propósito é, portanto, mais ligado à estratégia nietzschiana-foucaultiana da genealogia do que a qualquer história no sentido pleno. $\mathrm{O}$ fio genealógico que pretendo seguir aqui para expor, pelo menos, um dos múltiplos caminhos que ligam os estudos queer à teoria feminista que os precede, será o problema da fragmentação e proliferação, interna e fronteiriça, dos sujeitos do discurso. Como tentarei mostrar, o pensamento e a crítica "da" diferença sexual e de suas hierarquias foram, em geral, historicamente acompanhados por uma multiplicação de fraturas, uma proliferação de vozes feministas e distâncias críticas e, finalmente, uma problematização crescente da unidade do sujeito "mulheres" do feminismo. Nesse aspecto, a diferença entre a maior unidade do sujeito do discurso feminista e a sua irredutível plurivocidade no âmbito dos estudos queer não representaria, mais do que qualquer tipo de rutura, uma diferença de grau. Isto é, o que tentarei mostrar com uma breve aproximação às raízes do pensamento "da" diferença sexual e suas hierarquias, às distâncias de classe entre sufragistas e socialistas, ao abismo aberto entre o feminismo liberal e radical nos Estados Unidos, ao subsequente deslocamento deste último na direção das barricadas das sex wars e, transversalmente, à multiplicação de vozes críticas dos feminismos lésbicos, negros, chicanos, entre outros, para chegar na antessala dos estudos queer com o ataque ao pensamento "da" diferença sexual que representou a teoria da performatividade de gênero na obra de Judith Butler. 


\section{Os sujeitos do feminismo}

Para algumas autoras, a idealização da mulher e do feminino na literatura medieval constitui uma das fontes arqueológicas do feminismo. Em El origen de la mujer sujeto [A origem da mulher sujeito] (CERECEDA, 1996) se insiste, por exemplo, a partir do papel central da narratividade na constituição das posições sexuadas, nas ambiguidades próprias do papel atribuído às mulheres no desenvolvimento do amor cortês: o qual, por um lado, atribui um papel claramente passivo de "objeto de desejo", pelo outro, requer a liberdade da mulher em seu uso público da palavra ao conceder ou negar seus favores aos seus pretendentes. De fato, a reação misógina diante da idealização do feminino foi notória, especialmente, ao longo dos séculos $\mathrm{XIV}$ e XV, tanto na tradição clerical como na incipiente cultura secular burguesa. Porém, é claro que não podemos associar facilmente este tipo de "narrativa" com a constituição de um sujeito das políticas feministas: tratar-se-ia aqui principalmente de um discurso sobre as mulheres.

A importância que a articulação de uma voz própria tem para qualquer movimento emancipatório resulta evidente. Para Joan Kelly, por exemplo, a ocupação da primeira pessoa será justamente a marca a que leve a uma reconsideração geral do papel que pioneiras como Christine de Pizan ou Lucrezia Marinella e Mary Astell, no âmbito da Querelle de femmes, ocupam na gestação das reivindicações feministas (KELLY, 1982), apesar de que a historiografia feminista tenda a tomar as revoluções francesa e inglesa como pontos de partida. Porém, a masculinidade predominante no Renascimento aumentou, se possível, a precariedade das posições discursivas, e no espaço público num sentido mais geral, habitáveis pelas mulheres no mundo ocidental.

Já no âmbito da modernidade, será no contexto das mudanças trazidas pela Revolução Francesa, cenário de energéticos e heterogêneos movimentos pela igualdade de direitos das mulheres, onde esta articulação do sujeito da política feminista tenha lugar de uma forma evidente. O trabalho político de grupos como la Société des citoyennes républicaines révolutionnaires [A sociedade das cidadãs republicanas revolucionárias], composto exclusivamente por mulheres, junto com a publicação de obras "vindicativas" no sentido de Amorós (1997), como a Declaração dos direitos da mulher e a cidadã ${ }^{2}$ de Olympe de Gouges,

\footnotetext{
${ }^{2}$ Disponível em espanhol em: $<$ http://clio.rediris.es/n31/derechosmujer.pdf $>$
} 
em 1791, ou a Reivindicação pelos Direitos da Mulher por Mary Wollstonecraft, em 1792, conseguiram mudar o curso histórico do patriarcalismo próprio do Iluminismo. A articulação das reivindicações feministas representou de facto, pela luta e pela escrita, uma fragmentação irrecuperável do homem e do citoyen, os sujeitos de direitos "universais" da revolução francesa.

O sujeito "mulheres" continuaria o seu percurso politico no século XIX de mãos dadas com o movimento sufragista. A aquisição do direito ao voto e o acesso ao parlamento se apresentavam como objetivos inevitáveis. Nos Estados Unidos, o sufrágio coexistiu com as lutas abolicionistas, e chegou até a se inspirar nelas, a partir da comparação da situação histórica da mulher com a escravidão (ROWBOTHAM, 1980). Predominam, nesse contexto, os argumentos da inspiração universalista, bem como o recurso a "lei natural" como origem e fundamento dos direitos em jogo. Tais argumentos às vezes coexistiam com outros mais relacionados ao individualismo protestante, como exemplificado por The Women's Bible de 1895, obra de uma das sufragistas mais influentes, Elizabeth Cady Stanton (1997). Por outro lado, desde o início do século XIX, o avanço dos novos modos de produção capitalistas, junto com a falta de direitos civis da classe trabalhadora emergente, foi acompanhado por uma crescente organização internacional do socialismo e o anarquismo, entre os quais o feminismo foi conquistando seu próprio espaço, tanto no sentido político amplo quanto no estritamente teórico. Socialistas utópicos como Fourier chamavam a atenção para formas específicas de exploração da mulher e tornaram-se importantes defensores da independência econômica das mulheres, bem como da ideia de cooperação entre os sexos em igualdade de condições. Outras, como Flora Tristán, representante do feminismo socialista, defendia a profunda revalorização do papel das mulheres na sociedade e na importância crucial da educação das mulheres para o progresso da classe trabalhadora (2006).

Em relação com o marxismo, o feminismo foi distanciando-se cada vez mais das explicações de cunho biológico ou natural da diferencia sexual. Este processo foi facilitado, em parte, graças a que Engels tinha formulado em The Origin of the Family, Private Property and the State [A origem da família, da propriedade privada e do Estado] (1996), a questão da dependência dos modos de produção capitalistas da produção de mão de obra e, com ela, identificou a dedicação da mulher à esfera doméstica e reprodutiva (isto é, sua exclusão dos meios de produção propriamente ditos), como um elemento chave para o sustento da ordem capitalista. Isso, no entanto, permaneceria sendo um tema controverso dentro do próprio 
marxismo, devido à consideração generalizada da subordinação $d a$ mulher como uma peça secundária no conjunto de toda a exploração do proletariado. Apesar disso, as bases para a futura desnaturalização do sujeito "mulheres", especialmente nos análises da conjunção entre capitalismo e patriarcado, já haviam sido estabelecidas.

Este feminismo marxista representava uma alternativa frontalmente oposta ao do movimento sufragista, ao qual as marxistas consideravam como um movimento burguês incapaz de representar os interesses das mulheres operárias, apesar de sua defendida vocação interclassista. Marcando distâncias com as sufragistas, militantes e teóricas como Alexandra Kollontai ou a alemã Clara Zetkin contribuíram para aumentar o nível de organização do feminismo marxista, realizando eventos-chave como a Conferência Internacional das Mulheres em 1907, consolidando os elos teóricos entre as ordens econômicas e sexuais da opressão capitalista e patriarcal.

Porém, foi o feminismo anarquista quem mais diretamente enfrentou as aspirações do movimento sufragista. Nesse sentido, autoras como Emma Goldman representaram, no início do século passado, uma alternativa dupla, tanto ao reformismo institucional e ao domesticismo burguês das sufragistas, por uma parte, bem como às crescentes pretensões de controle do espaço doméstico que, cada vez mais claramente, regiam a sociedade comunista, pela outra. Em relação às sufragistas, e apesar de não entender "por quais razões físicas, psicológicas e morais a mulher não possui os mesmos direitos que o homem", Goldman foi muito crítica com a aspiração sufragista por partilhar o modelo de estado com os homens ou, nas suas palavras, por conquistar o privilégio de ser "juiz, carcereiro ou verdugo" (GOLDMANN, 1911). Além do que, denunciou o modo em que o movimento sufragista repetia o gesto excludente sobre outros grupos de mulheres, como resultado do seu marcado puritanismo:

A mulher, essencialmente tida como puritana, no sentido moral, é naturalmente santa, sendo, portanto, incansável em seus esforços para converter aos outros em boas criaturas, como ela acha que deveriam ser. Daí que em Idaho, [o movimento sufragista] se desligou de sua irmã de rua, de reputação duvidosa e declarou-a inepta para votar (...). Além disso, as leis são maravilhosas. Não precisam se estender muito sem que seu espírito se abra para todas as pragas do inferno. A prostituição e os jogos de azar nunca floresceram lá com mais exuberância como agora que têm as leis contra eles (GOLDMANN, 1911; cursivas minhas). 
Quando Goldmann, com ironia, refere-se assim "a mulher", no mesmo texto em que manifesta a sua franca admiração pela "mulher russa que possui em alto grau o valor de afrontar as penas do inferno pelo seu ideal!", mobiliza de facto numerosos sentidos para o sujeito das políticas feministas. Este inclui aqui, no mínimo, às sufragistas de diferentes estados e às comunistas russas, mas também a aquelas que, como as prostitutas cuja exclusão denuncia Goldmann, estão sendo excluidas pelas sufragistas. Assim, a partir do conflito entre diferentes perspectivas feministas, com agendas políticas muito distintas, competindo pela atribuição do mais alto grau de internacionalismo e interclassismo possível, ficaram claras algumas das dificuldades e resistências inerentes ao projeto para desenvolver o feminismo representacional intrínseco ao pensamento e das políticas feministas. Ou também, em outros termos, o fracasso constitutivo de qualquer tentativa de universalizar um sujeito político que foi sempre, em última instância, tão fragmentário como indelimitável. Esta recorrente fratura e estas tensões nos margens do significante "mulheres" atravessará, como é sabido, as décadas, sublinhando a indissociabilidade entre qualquer projeto feminista crítico e a preocupação diante da pergunta: quem são as mulheres?

\section{O segundo gênero}

A progressiva (embora insatisfatória) incorporação da mulher no mercado de trabalho, junto com a sucessão de consumações das reivindicações sufragistas, levaria a uma sensação pouco produtiva de fim da viagem na teoria e nas políticas feministas. Nesse impasse, Le deuxieme sexe [O segundo sexo] (1949) funcionou como um poderoso mobilizador que redefiniu a opressão da mulher quando o direito ao voto tinha deixado de ser a prioridade e a principal força coercitiva para o movimento feminista. $\mathrm{O}$ novo relato do processo de aquisição de gênero (feminino), a partir da ação de forças sociais muito diferentes (educativas, econômicas, médicas, etc.), tornou-se uma peça-chave da análise da violência patriarcal, e abriu as portas para o desenvolvimento de uma perspectiva construcionista sobre a identidade genérica. De fato, é comum aludir a essa mesma obra ao se referir à distinção operativa entre sexo e gênero, que se tornaria um poderoso instrumento analítico para questionar a necessidade biológica dos atributos tradicionalmente associados ao sexo feminino, bem como suas consequências na divisão genérica dos papéis sociais (familiares, laborais, etc.). A origem do conceito também está diretamente ligada, apesar de tudo, ao campo da medicina e à manipulação cirúrgica e hormonal dos corpos intersexuais na década de 1950 - em particular, 
ao trabalho de John Money sobre a redesignação do "gênero" - o que levou a teóricos queer como Paul B. Preciado a reclamar sua herança biotecnológica ${ }^{3}$.

Em parte devido as novas ferramentas teóricas, a geralmente referida como "segunda onda" do feminismo, associada à década dos anos sessenta, pode ser descrita como uma profunda reconceitualização da opressão genérica, uma vez superadas as desigualdades mais formais (o direito ao voto foi o símbolo paradigmático da luta por igualdade de direitos, apesar de todas as outras discriminações legais que o acompanhavam), que tinham ocupado, sobretudo, a atividade das sufragistas. Na linha aberta por Beauvoir, a nova tarefa do feminismo será desenvolver teorias e políticas feministas diante das desigualdades genéricas que careciam, frequentemente, de uma concretização jurídica ou legal ou, expressada mediante uma fórmula que se tornará usual, em explicitar "o problema que não tem nome"4 .

Já ao longo dos anos sessenta, e principalmente no final da década, o feminismo liberal desenvolveu uma relação antagônica com o Movimento de Libertação da Mulher, principal veículo das demandas do incipiente feminismo radical. Este último é geralmente entendido, por sua vez, como uma reação à retórica do feminismo liberal. Em vez de falar de "desigualdades", as radicais se referiram explicitamente ao patriarcado e à opressão da mulher, da qual considerariam cúmplice, bem como beneficiário, a todo membro do sexo masculino. Consequentemente, concebem a luta feminista como a abertura de um espaço social exclusivamente feminino e são particularmente ativas na criação de todos os tipos de redes e grupos de apoio entre as mulheres. Desta forma, foi-se abrindo uma importante fratura entre os feminismos da diferença - na forma do separatismo radical - e os feminismos da igualdade que vem com desconfiança o enaltecimento da diferença genérica como parte da agenda feminista.

\footnotetext{
${ }^{3}$ A diversidade de possíveis caminhos genealógicos do conceito de gênero levou autores como João Manuel de Oliveira a explorar os espaços teóricos em que o conceito é concebido sem pretender construir "a" história de sua evolução em qualquer sentido convencional. Assim, por exemplo, em "O rizoma 'gênero': cartografia de três genealogias" explora-se a influência do trabalho de Beauvoir sobre a noção de gênero, justapondo-o ao problemático behaviorismo de gênero de John Money e, também, a uma das influências diretas da teoria da performatividade de gênero de Judith Butler (sobre a qual retornaremos mais adiante): o tratamento da feminilidade como mascarada no trabalho do teórico psicanalítico Joan Riviere. Tudo isso, tratando o gênero "como um rizoma [de Deleuze e Guattari], pressupondo que gênero e sua história não podem ser representados de modo arborescente com uma raiz, um tronco, galhos e folhas" (OLIVEIRA, 2012: p. 35).

${ }^{4}$ Obras como La mística de la feminidad [A mística da feminilidade], de Betty Friedan (1974), publicada em 1963, pretendiam precisamente isso, ao questionar os papéis rígidos que favoreciam o confinamento das mulheres ao espaço doméstico e aos papéis de mãe e esposa. Fridan também contribuiu para a formação do grupo ativista mais emblemático do feminismo liberal, o National Organization for Women (NOW), preocupada principalmente por aumentar a presença feminina no espaço público, tanto no conjunto do mercado de trabalho como em postos de poder estritamente políticos.
} 
De qualquer forma, a influência do feminismo radical continuou crescendo, especialmente nos Estados Unidos, influenciando inclusive ao feminismo liberal (que tomou ideias como a criação de grupos de mulheres, e adotou o slogan "o pessoal é político", que inicialmente rejeitou por tornar o "privado" um centro de luta política), bem como a praticamente substituí-lo nos anos setenta, precisamente em sua forma mais essencialista e separatista. A criação do New York Radical Feminists [Feministas Radicais de Nova York] e a publicação de obras como a Sexual Politics [Política sexual] de Kate Millet (1970) e The Dialectic of Sex: The Case for Feminist Revolution [A dialética da sexualidade: Em defesa da revolução feminista] de Shulamith Firestone (1970), nos inícios da década dos 70, marcaram o desenvolvimento de uma conjunção de marxismo, psicanálise (de Freud a Reich) e póscolonialismo para o qual o patriarcado representava, na realidade, o sistema básico de dominação (acima da classe ou da raça).

Frequentemente, distingue-se o "feminismo cultural"5 como uma radicalização de, pelo menos, alguns dos pressupostos do separatismo próprio do "feminismo radical". Radicalização que teria ido de mãos dadas, desde o final dos anos setenta, com a despolitização progressiva do movimento, fruto do distanciamento das abordagens freudomarxista e socialista. Deste modo, o feminismo radical teria ido se separando da crítica direta ao sistema capitalista, o qual consideraria como um elemento próprio da cultura patriarcal a ser superada: não se trata aqui da transformação do sistema baseado no confronto político, mas sim de abandoná-lo completamente por meio da construção de todo um socius alternativo: uma cultura de mulheres concebida como uma alteridade radical a respeito da razão patriarcal.

Naturalmente, as relações entre o patriarcado e o capitalismo foram, e continuam a ser, objeto de múltiplas controvérsias. Diante da rejeição do feminismo radical para subordinar ou mesmo igualar a questão do gênero com a do capital, as feministas da tradição socialista buscavam revisões das premissas marxistas que extraíam o máximo potencial do conceito de "luta de classes" no estudo da opressão das mulheres como classe. Boa parte das tentativas

\footnotetext{
${ }^{5}$ Especialmente significativo para o feminismo cultural foi o trabalho de Carol Gilligan sobre as diferenças características do desenvolvimento moral - no campo da psicologia evolutiva - do gênero feminino, embora sua influência não termine aí. Como aponta Teresa de la Vieja, "as conhecidas análises de C. Gilligan dos anos setenta deram entrada à perspectiva de gênero - por fim, outra voz - em diferentes campos argumentativos, a Epistemologia (S. Harding, S. Hekman, H. Longino), a Ética, entre a justiça e o cuidado, (I. Young, N., Fraser, H. Pauer Studer, S. Moller Okin), Jurisprudência (Z. Eisenstein, Ch. Littleton), uma teoria Política de orientação não contratualista (C. Pateman, V. Held, J. Mansbridge, S. Benhabib). É por isso que hoje é mais apropriado falar de feminismos". (2004, p. 24).
} 
nessa direção caminharam de mãos dadas com o feminismo socialista anglo-saxão, ao longo dos anos setenta.

Estes coincidiam, em geral, na necessidade de dispor de um "sistema dual" para abordar a opressão. Isso tornaria possível distinguir a opressão que sofrem no campo dos meios de produção, no âmbito da reprodução e do trabalho doméstico, uma vez que este último foi identificado como um espaço de opressão especificamente patriarcal. O capitalismo e o patriarcado constituem diferentes sistemas de opressão, exigindo, cada um deles, sua própria metodologia de análise. Em qualquer caso, a abolição de ambos foi considerada igualmente necessária na luta pela emancipação “da mulher”. Para isso, autoras como Zillah Eisenstein afirmaram a necessidade de estudar o "capitalismo patriarcal" em suas formas históricas concretas, superando as limitações analíticas do marxismo quanto do feminismo (Eisenstein, 1980). Outras, como Carol Pateman (1995) ou Heidi Hartmann (1980), revisaram as teorias do contrato social, o qual descrevem como um "pacto entre homens" que estabelece as bases de uma aliança masculina interclassista em relação à qual as mulheres não ocupariam mais do que papel de "moeda de troca". Algumas autoras contemporâneas (por exemplo, Nancy Fraser, 1995), repensaram essa dicotomia na tentativa de oferecer uma teoria realmente "unificada" de ambas formas de opressão, ao contrapor, à distinção analítica sua indivisível interligação em cada um dos seus pontos de aplicação.

Apesar das diferenças, o feminismo radical e o mais recente feminismo cultural (para algumas, a evolução progressiva de um único movimento) compartilhariam o projeto de fundar uma cultura produzida por e para as mulheres, e consideravam estas como um sujeito político sem fraturas nem diferenças internas que exigissem um tratamento específico. Esse lugar comum do movimento feminista começaria a ser questionado, em profundidade, desde o final dos anos setenta, com o surgimento de um crescente número de críticas que questionam vários aspectos da política de identidade do feminismo e que podem ser considerados, em muitos casos, antecessoras da investida tipicamente queer aos limites do sujeito das políticas feministas.

\section{Genealogias Queer}

É neste sentido crucial assinalar, em primeiro lugar, o trabalho das feministas lésbicas que mais vigorosamente questionaram a própria possibilidade da unidade da ação política em torno do significante "mulheres". Monique Wittig é, sem dúvida, uma das autoras que mais 
radicalmente tem levantado sua rejeição ao entendimento ahistórico da diferença sexual, ao qual opõe o tratamento das diferenças entre os sexos nos próprios termos da luta de classes. Uma luta que, a partir das "mulheres", enquanto classe social constituída por relações históricas de exploração, teria como resultado "o desaparecimento dessa classe" (assim como seu antagonista "natural", a classe dos "homens", definido pelo exercício da opressão). O nome que Wittig dá àquela relação de exploração não será outro senão o da heterossexualidade, enquanto instituição política. Para Wittig, o caráter naturalizado da diferença sexual, bem como as qualidades associadas a um ou outro sexo (e à construção do que Wittig chama do "o mito da mulher") é o principal alvo de sua crítica geral das categorias sexuais, o qual resulta em uma divisão entre os conceitos de "lésbica" e "mulher":

A lésbica é o único conceito que conheço que está além das categorias de sexo (mulher e homem), uma vez que o sujeito designado (lésbica) não é uma mulher, nem economicamente, nem politicamente, nem ideologicamente. O que faz a mulher é uma relação social específica com o homem, uma relação que já nos referimos como "servidão", uma relação que implica obrigação pessoal e física, bem como uma obrigação econômica (residência forçada, trabalho doméstico, deveres conjugais, produção ilimitada de crianças, etc.) uma relação da qual as lésbicas escapam recusando-se a permanecer ou a tornar-se heterossexuais. (WITTIG, 2006)

Desse modo, Wittig transforma a figura "da lésbica" em um enclave privilegiado da dissensão do sistema heterocentrado, por um caminho paradoxalmente oposto às abordagens dominantes no feminismo radical (também em sua vertente separatista lésbica). Diante deste último, "a lésbica" de Wittig habita um espaço político desprovido de idealizações sobre as relações entre as mulheres e dispensa qualquer reivindicação de diferenças associadas a um modelo particular - biológico ou cultural - de feminilidade. Em sua crítica ao que batiza como heterofeminismo, Wittig substitui a preocupação pelo patriarcado, como tal, com a crítica da heterossexualidade como um sistema de (re)produção hierárquico e normativo dos sujeitos. Mesmo para muitas das teóricas que mais tarde irão criticar o projeto de Wittig, ao compreendêlo como uma aposta por uma política lésbica localizada em um "além" da historicidade própria da construção social do gênero, ensaios como "One is Not Born a Woman" [Não se nasce mulher] ou "The Straight Mind" [O pensamento heterossexual] tiveram uma influência determinante em sucessivos questionamentos do caráter natural do sexo e da diferença sexual. 
Embora seja verdade que o feminismo radical veio a postular o lesbianismo como uma consequência natural da consciência política da opressão da mulher, ele nunca questionou o papel da cultura e as relações de dominação na construção da matriz epistemológica pela qual as características físicas chamadas sexuais (“em si mesmas, tão neutras quanto qualquer outra, mas marcadas pelo sistema social"; WITTIG, 2006: p. 34) tornam-se um critério de diferenciação tão natural quanto a raça poderia ser para o "racismo científico". Diferenciação que constituiria, além disso, a condição mais evidente de possibilidade da heterossexualidade normativa. Dessa forma, Wittig abriu o caminho para formulações feministas que abandonam o aparente fundamento essencial bio-ontológico do discurso crítico para repensar a questão do gênero num marco radicalmente construccionista em termos históricos e, também, linguísticos.

Também a antropóloga americana Gayle Rubin faria da análise da heterossexualidade como um sistema de dominação, política e econômica, uma das preocupações centrais de sua obra. Suas análises da heterossexualidade compulsória e do sistema sexo/gênero aprofundaram a possibilidade de teorizar o sexo como uma construção política e não biológica, numa época em que a maioria do feminismo acreditava na necessidade de ter um fundamento a-cultural do sexo, das diferenças de gênero e mesmo da possibilidade de desenvolver uma política feminista. Apesar disso, suas críticas ao crescente componente normativo do feminismo radical têm sido muito influentes para uma ampla variedade de discursos, tanto dentro do próprio feminismo quanto, já nos anos noventa, nos posteriores desenvolvimentos das teorias queer.

As preocupações de Rubin oscilam entre as temáticas próprias da segunda onda do feminismo, como a busca de alternativas às limitações da abordagem marxista sobre as questões sexogenéricas e indagações em torno as políticas de certas contraculturas sexuais. Contudo, a ponte entre as duas questões, a saber, a identificação da divisão sexual do trabalho e da heterossexualidade como base das estruturas de parentesco apresentadas por Lévi-Strauss, permite também a leitura da obra de Rubin como uma operação de transformação crítica interna em relação ao próprio feminismo.

Em qualquer caso, Rubin aspirava precisamente romper os laços entre a investigação da sexualidade e as políticas e teorias de gênero (RUBIN, 1989), em grande parte por causa de seu descontentamento com as atitudes cada vez mais normativas e conservadoras de uma parte do feminismo radical. Para Rubin, a reificação de certas formas de relacionamento entre mulheres e, especialmente, das formas politicamente corretas de se relacionar entre lésbicas 
(incluindo, é claro, práticas sexuais), tinha feito do feminismo um discurso cada vez mais constritivo e exclusivo, capaz de catalogar as práticas e pautas de relacionamentos compatíveis com o fim da emancipação da mulher e de condenar aquelas que, a seu ver, reconsolidaram os valores de dominação e hierarquia genérica característicos do patriarcado e da heterossexualidade, como aconteceu com relações butch/femme, especialmente desprezadas pela ala conservadora do feminismo radical.

Enquanto Gayle Rubin fazia o trabalho de campo sobre a cultura do gay-leather em San Francisco, muitas feministas consideraram a cultura gay masculina uma influência perigosa para o feminismo e, especialmente, sobre os interesses do movimento lésbico. Como a própria Rubin explica em uma publicação recente:

Muitas feministas condenaram duramente as drag queens, os travestis, o sexo em público, a promiscuidade entre homens gays, a masculinidade gay, os de couro, o fist fucking, o cruising gay, etc. Eu não podia me resignar a aceitar esses tópicos segundo os quais todos esses tipos eram terríveis e antifeministas; eu considerei este discurso, sim, um ressurgimento da homofobia (RUBIN, 1994: p.76).

Dessa forma, Rubin acusa o feminismo separatista, ao invés das práticas ou papéis genéricos de certas contraculturas sexuais, de reproduzir a violência que exclui do sistema heterocentrado.

Igualmente comprometida com a reconciliação dos interesses dessas contraculturas com o feminismo se manifestava Adrianne Rich, dentro do marco teórico que associa a heterossexualidade e a produção social de gênero. Esse aspecto teria permanecido praticamente inquestionável pela tradição feminista ou, mais explicitamente, pelo feminismo heterocentrado. A maioria dos estudos feministas sobre questões como a maternidade, as relações familiares, etc., partiam de uma naturalização inquestionável da heterossexualidade, a qual Rich opõe a necessidade de analisá-la "como uma instituição política que diminui o poder das mulheres" (RICH, 1986: p.160).

Para minar o poder normativo dessa instituição, Rich proporá às feministas que cultivem relações entre mulheres sob a orientação de um conceito de continuum lésbico, que proporcionaria a oportunidade para o exercício da resistência às estruturas de dominação que regulam as relações entre os sexos e, especialmente, entre os sujeitos do "mesmo" sexo. As mulheres teriam sofrido, com a negação histórica da possibilidade do amor lésbico, um 
interessado empobrecimento de suas possibilidades de estabelecer laços afetivos profundos e significativos entre elas, bem como de resistir efetivamente às instituições heteronormativas e às múltiplas formas de subordinação das mulheres ao poder patriarcal. Por outro lado, apesar de sua aceitação, enquanto feminista radical, da diferença sexual em seu conceito do continuum, Adrianne Rich foi uma das vozes que mais prontamente denunciou aquela fratura interna do sujeito mulheres que, de fato, rapidamente se tornaria uma das questões mais debatidas com consequências de longo alcance para o feminismo em si. Refiro-me à praticamente total desatenção da tradição feminista ao que costumamos resumir, de forma tão recorrente quanto insatisfatória, como diferenças de classe, étnicas e raciais.

A incorporação dessas variáveis à teoria feminista representará a queda de um certo estado de auto complacência que caracterizou os momentos mais agitados do feminismo radical da década de 1970. Especialmente no que diz respeito à postulação da unidade política das mulheres não mais como objetivo, mas como o pressuposto inicial de qualquer política feminista. Uma crença que tornava muito difícil o reconhecimento de que o feminismo operava, melhor dizendo, como a agenda política de um grupo muito específico de mulheres, majoritariamente de classe média e ocidentais, que repetiam os gestos da exclusão e da opressão em relação a tantas outras mulheres a partir do seu próprio privilégio económico e etnocêntrico.

\section{Fogo cruzado}

Esta foi justamente a situação denunciada por uma ampla variedade de trabalhos escritos a partir de posicionamentos identitários complexos, e que surgiram, em muitos casos, da necessidade de enfrentar tanto a cultura patriarcal das comunidades de procedência, quanto ao classismo e racismo presentes na política quotidiana dos principais movimentos feministas. Assim por exemplo, a publicação de This Bridge Called my Back: Writings by Radical Women of Color (MORAGA, 1988) coleção de ensaios, narrativas pessoais e poemas, pelas chicanas Cherrie Moraga e Gloria Anzaldúa, alcançou um grande impacto ao reunir uma variedade de vozes feministas e lésbicas chicanas, latinas, asiáticas e afro-americanas que ofereciam perspectivas incomuns, desconhecidas e, em grande medida, perturbadoras, para a maioria do feminismo branco. A mesma Anzaldúa publicou, alguns anos depois, outra obra emblemática desses assaltos à visão unitária da política de identidade, Borderlands/ La Frontera: The New Mestiza (1987) onde, misturando poesia e ensaio, além do inglês e do espanhol, ela abordaria em termos como esses sua identidade mestiça: 
To live in the borderlands means you

Are neither hispana india negra española

ni gabacha, eres mestiza, mulata,

half-breed caught in the crossfire

between camps

while carrying all five races on your back

not knowing which side to turn to, run from.

(ANZALDÚA, 1987: p. 194)

A sensação de estar "entre dois fogos", a qual Anzaldúa se refere aqui, é percebida de forma bastante enfática em uma grande variedade de publicações ao longo da década. Do lado do feminismo negro e/ou afro-americano, continuaram fazendo todo tipo de análise das interseções entre opressões raciais, de gênero, heterossexistas e de classe, em antologias como All the Women Are White, All the Black Are Men, But Some of Us Are Brave (HULL, BELL \& SMITH, 1982), e Home Girls: A Black Fem Anthology (SMITH, 1983); o trabalho inicial da afro-americana bell-hooks, Ain't I a Woman: black women and feminism (1981), junto com outras que reuniram vozes feministas negras e judaicas, como Yours in Struggle: Three Feminist Perspectives on Anti-semitism And Racism (BULKIN \& SMITH, 1984), Nice Jewish Girls: A Lesbian Anthology (TORTON, 1982), sobre identidade lésbica judaica, e inúmeras publicações, incluindo aquelas protagonizadas pelas mulheres asiáticas americanas, como Making Waves: an Anthology of Writings by Asian American Women (AWUC, 1989), já quase no final da década.

Assim, a década dos anos noventa foi precedida por uma reflexão heterogênea sobre os limites da política de representação e, em particular, sobre os aspectos mais problemáticos do conceito de identidade. É difícil subestimar a influência dos desafios colocados por esta conjunção de críticas aos componentes universalistas das políticas de identidade (não apenas feministas, mas também aquelas que dominaram o discurso da política gay e lésbica), tanto no lado do sistema sexo/gênero (Monique Wittig, Gayle Rubin, Adrienne Rich, etc.) quanto pelo lado do colonialismo e os eixos raciais e de classe. Assim o demonstraram autoras como as já mencionadas Gloria Anzaldúa, Cherrie Moraga, bell hooks, juntamente com outras como Gayatri Spivak, autora do influente Can the Subaltern Speak? [Pode o subalterno falar] (1985) onde evidenciava as dificuldades de articulação de uma subjetividade sexuada própria desde os espaços pós-coloniais, diante do fogo cruzado do patriarcado da própria tradição e dos gestos salvíficos caracterizados com a conhecida frase "homens brancos salvando mulheres pardas de 
homens pardos" (SPIVAK, 1985: p. 296). Como bem mostraram as teorias da interseccionalidade de autoras como Kimberlé Crensahaw (1993), as tentativas de pensar separadamente as diferentes categorias de opressão (gênero, classe, raça ...) não podiam deixar de estar condenadas ao fracasso. Daí que, como expressaram claramente feministas decoloniais como María Lugones, a denúncia do apagamento imperialista das vozes das mulheres de cor a que Spivak se referiu é, ademais, igualmente válida quando se trocam "homens brancos" por feminismos brancos:

Com o desenvolvimento dos feminismos do século XX, não se fizeram explicitas as conexões entre gênero, classe e heterossexualidade como racializados. Esse feminismo focalizou sua luta e seus modos de conhecer e teorizar, contra uma caracterização das mulheres como frágeis, tanto corporal quanto mentalmente, confinadas ao espaço privado, e como sexualmente passivas. Mas não explicou a relação entre essas características e a raça, uma vez que elas apenas constroem a mulher branca e burguesa. Dado o caráter hegemônico que a análise alcançou, não só não explicitou, mas ocultou sua relação. Começando o movimento de "libertação da mulher" com a caracterização da mulher como alvo da luta, as feministas burguesas brancas se ocuparam em teorizar o significado branco de ser mulher como se todas as mulheres fossem brancas (LUGONES, 2008: p. 94).

Diante dessas tensões, uma das principais preocupações dos discursos feministas emergentes tinha a ver com a necessidade de entender como uma política identitária de vocação universalista e emancipatória podia implantar seu próprio gesto opressor sobre outros posicionamentos identitários. Esse é o problema enfrentado por teóricas como Elizabeth Spelman em Inessential Women: Problems of Exclusion in Feminist Thought (1988) ${ }^{6}$ ou, um pouco mais tarde, Joan Scott, através de suas críticas à ideia de "experiência" como fundamento e critério unificador dos posicionamentos identitários (1991), seguidas por Judith Butler, que repensaria o problema, no mesmo ano, com Gender Trouble [Problemas de Gênero] (2002). Este último, juntamente com outros também publicados no início dos anos 90, como a Epistemology of the Closet [Epistemologia do Armário], de Eve Kosofsky Sedgwick (1990), tornou-se uma das referências clássicas daquilo que logo seria conhecido (a partir da denominação proposta em "Queer Theory: Lesbian and Gay Sexualities. An Introduction"7 de

\footnotetext{
${ }^{6}$ Onde Spelman coloca sua crítica ao "realismo de gênero", isto é, a ideia de que todas as mulheres têm algo em comum que as define como tal.

${ }^{7}$ Lauretis propõe esta denominação para políticas de resistência que articulam "os discursos e as práticas da homossexualidade", em relação às variáveis étnicas e raciais (1991, p. iii).
} 
Teresa de Lauretis;1991) como teoria(s) queer. Em diálogo com autores como Lévi-Strauss, Michel Foucault, Jacques Lacan, Monique Wittig e algumas autoras do feminismo da diferença francesa, como Julia Kristeva e Luce Irigaray, e com uma clara influência da desconstrução derridiana, Gender Trouble [Problemas de Gênero] oferece o que Butler apresentará, no prefácio à edição de 1999, como uma "reformulação especificamente feminista" (BUTLER, 2002: ix) do pós-estruturalismo.

Como referia na introdução, Judith Butler, desde uma perspectiva foucaultiana, entende que o discurso das políticas de identidade, incluindo o feminismo, não apenas dá conta da realidade da opressão de certos grupos, mas também ocupa um papel fundamental na formação e constituição do próprio sujeito de tais políticas. Desta forma, o discurso feminista colocaria inevitavelmente em jogo diferentes modelos de feminilidade normativa, cuja especificidade cultural se torna evidente nos conflitos que ocorrem em torno a seu limites étnicos, raciais, econômicos e sexuais-. Coincidindo com questionamentos anteriores da categoria do sexo, o trabalho de Butler reflete uma rejeição enérgica da descrição de traços genéricos e sexuais como uma expressão de uma essência de identidade natural, biológica ou ontológica. No caso concreto de Butler, essa questão se coloca em relação direta com o núcleo da crítica de Derrida à teoria dos atos de fala de J. Austin (1962).

Para este último, o discurso, além de suas funções expressivas ou descritivas, deve ser analisado em relação ao seu poder de produzir transformações efetivas dos contextos sociais nos quais ele intervém (o que Austin chamou de "força performativa" do ato de fala) ${ }^{8}$. Derrida (1972) chamou a atenção para o papel desempenhado pela repetição histórica de significantes na produção de qualquer efeito do uso de performativos. Tal repetição desencadeia um processo de sedimentação pelo qual as palavras que usamos se tornam inteligíveis ao se tornarem reconhecíveis como uma nomeação mais na cadeia histórica dos usos dessas mesmas palavras. Nesse sentido, a própria "tradução cultural” à qual Butler se referiu para explicar seu próprio trabalho representa, mais do que uma invenção, ao estilo Rorty, um novo vocabulário pósestruturalista ou feminista, uma recitação crítica de ambos cujos efeitos inesperados ainda se sentem nos mais variados espaços do pensamento crítico.

\footnotetext{
${ }^{8}$ Expressões como "os declaro marido e mulher", "a sessão é aberta”, são exemplos clássicos de performativos, embora progressivamente a performatividade acabasse sendo concebida como uma dimensão própria de qualquer fórmula linguística, antes do que como uma definição de uma categoria especial de afirmações.
} 
Estendendo essa análise para a dos performativos de gênero, entendidos como um conjunto de signos -linguísticos ou não- que entram em cena na leitura do gênero de qualquer sujeito, Butler entende o próprio gênero como um efeito de nossa capacidade de recitar adequadamente as normas que regulam a produção social do gênero. A performatividade constituiria, então, como os dispositivos disciplinares analisados por Foucault, uma força fundamentalmente homogeneizadora. Mas Butler também enfatiza outros aspectos chave do tratamento derridiano da performatividade. Pois, embora todo performativo precise da repetição do conhecido para produzir seu efeito, é inútil, por outro lado, tentar fixar qualquer sentido único ou original ao longo da cadeia de repetições: cada um deles representa a ocasião para o deslocamento do significado do performativo, para a produção de uma repetição alterada e diferente, que subverta inclusive os efeitos previamente autorizados (BUTLER, 2002: p.13) para o mesmo 9 .

Consequentemente, Butler sugere que toda ocasião em que recitamos um performativo de gênero representa, inevitavelmente, uma ocasião para a recontextualização e/ou subversão de identidades genéricas normativas e, em consequência, do caráter naturalizado da diferença sexual que as sustentaria. Sobretudo, onde é necessária a conquista dessa legitimação social e reconhecimento que é concedido em detrimento da exclusão e da abjeção social de sujeitos não normativos. O processo de disseminação subversiva dos performativos sexogenéricos formaria, em última análise, parte de uma estratégia de proliferação genérica que desestabilizaria os modelos normativos de identidade, e que deve seu potencial crítico à sua relação íntima com as lições de proliferação de vozes feministas nos eixos de classe, raça, gêneros e, claro, sexualidades.

\section{A caminho da conclusão}

A teoria da performatividade de gênero impactou o conjunto das teorias feministas. Isso se deveu em parte ao fato de que propostas como a de Butler e boa parte dos estudos queer que se seguiram, devolveram a noção de sexo ao espaço cultural geralmente reservado ao gênero - em consonância com a ideia foucaultiana de "sexo" como um elemento-

\footnotetext{
${ }^{9}$ Sobre a recepção butleriana da categoria da performatividade a través da crítica derridiana e o seu impacto sobre a teoria feminista ver Del texto al sexo. Judith Butler y la performatividad (PÉREZ NAVARRO, 2008).
} 
chave no "dispositivo da sexualidade"10 - , com a consequência de que, entre outras coisas, questiona-se não apenas a conveniência, mas a mera possibilidade de delimitação prévia do sujeito "mulheres" como ponto de partida para políticas feministas.

Assim se explica a reação defensiva de autoras ligadas ao projeto filosófico da modernidade, como Seyla Benhabib, de quem Butler foi aluna, e que a partir de sua orientação habermasiana, entende que desconstrução e biopolítica seriam pouco menos que uma influência nefasta sobre a filosofia em geral e nas teorias e políticas feministas em particular. Assim, embora Benhabib reconheça o valor de uma crítica feminista que confronta a "crítica da racionalidade ocidental vista sob a perspectiva das margens, do ponto de vista daqueles que são excluídos, suprimidos, deslegitimados, transformados em loucos, imbecis ou infantis" (BENHABIB apud GUERRA, 1997: p. 149), teme, no entanto, que um corte demasiado agudo com as aspirações do projeto iluminista -e a problematização das categorias de sujeito, autonomia, responsabilidade, etc.—como em sua opinião pretende o "pós-feminismo" (na linguagem de Benhabib) butleriano, teria o efeito de minar a capacidade de agência das políticas feministas.

Três décadas depois, pode-se afirmar com certa segurança que a teoria da performatividade de Butler, os diálogos que ela mesma praticou e, é claro, aqueles que ela continua a inspirar com filosofia pós-estruturalista representam uma incursão feminista em áreas que antes eram vedadas a sua potência crítica. Em particular, a problematização da categoria de sujeito com que Benhabib estava tão preocupada, assim como muitas outras defensoras ferrenhas dos pressupostos do projeto iluminista, como Celia Amorós no estado Espanhol (PÉREZ NAVARRO, 2012), não faz senão responder ao desafio da proliferação de vozes já mencionadas no cerne das políticas feministas. Assim, se muitas vezes as insuperáveis divisões, correntes, fraturas internas sempre acompanharam o pensamento feminista, não é menos verdade que estas alcançaram um ponto crítico nas duas últimas décadas no contexto geográfico e político no qual a obra de Butler é gestada, especialmente na forma de crítica ao feminismo liberal, por um lado, e nas derivações dominantes do radical, pelo outro. Refiro-me,

\footnotetext{
10 “Ao longo das linhas em que o dispositivo da sexualidade foi desenvolvido desde o século XIX, vemos elaborarse a ideia de que há algo mais do que corpos, órgãos, locais somáticos, funções, sistemas anatomofisiológicos, sensações, os prazeres; algo mais e algo diferente, algo dotado de propriedades intrínsecas e de leis próprias: o 'sexo'"(FOUCAULT, 2005: p.85).
} 
em especial, às críticas mencionadas provenientes de um amplo espectro de feminismos lésbicos, negros e chicanos, entre outras diferenças sexuais, étnicas, raciais e de classe ${ }^{11}$.

O que é constituído como resposta, de certo modo, na teoria da performatividade não é, evidentemente, uma fragmentação do sujeito da luta feminista. Tratou-se, mais bem, de entender que, como explica a própria Butler, "a desconstrução da identidade não é a desconstrução da política; em vez disso, estabelece como política os termos próprios com os quais a identidade é estruturada" (2002, p. 189). Tal desconstrução ou, em outras palavras, tal exercício de tradução cultural do pós-estruturalismo para o feminismo pode ser lido, como uma tarefa feminista e/ou queer, como um momento de reflexividade política, no sentido filosófico da crítica voltada para si mesma, em que se impôs, para o pensamento feminista, a necessidade de resistir à violência exercida em nome de um excesso de segurança no que diz respeito ao significado e limites do sujeito "mulheres" e, por tanto, da própria agenda política do feminismo.

Nesse sentido, a crítica queer, embora suas genealogias existissem muito antes dos primeiros trabalhos de Butler, encontra nela um de seus impulsos mais reconhecíveis. No que a teorização queer tem justamente de incipiente é que coloca, em particular, a atenção às margens e exteriores constitutivos daquele sujeito cuja natureza escapou ao escrutínio crítico. Em outras palavras, a crítica queer facilitou que o trabalho crítico do feminismo fosse ampliado para abranger as fronteiras nas quais o citado sujeito entra em contato, na forma de múltiplas fricções, com seus exteriores constitutivos: com seu ataque frontal à topografia biológica e transhistórica em geral de tal sujeito, a teoria da performatividade torna-se a abertura do pensamento feminista a um pensamento político das perturbações que inevitavelmente ocorrem nas margens da construção do sujeito da luta coletiva.

Nesse sentido, não surpreende que tanto o trabalho de Butler quanto as teorias queer tenham servido não apenas para recuperar o feminismo para aqueles que habitam espectralmente nas suas fronteiras, mas para pensar sobre a violência exercida em nome de um excesso de seguranças ontológicas, não apenas no âmbito da teoria feminista, mas também da antropologia, da filosofia ou da psicanálise. Que tais críticas tenham contribuído a fazer mais

\footnotetext{
${ }^{11}$ É difícil subestimar, em qualquer caso, a importância que para o desenvolvimento das teorias queer teve a sincronicidade desse tipo de crítica "interna" do feminismo que se produzia, no final da década de 80 , e a dupla dissidência que representava o ativismo queer no final da década: frente ao silenciamento e desídia institucional da epidemia do VIH, por uma parte, e frente às apolíticas assimilacionistas dos principais lobbies gays e lésbicos nos Estados Unidos, pela outra (PÉREZ NAVARRO, 2009).
} 
permeáveis também, em caminhos de ida e volta ao largo das últimas décadas, os muros entre a academia e o ativismo não pode senão deixar de sublinhar a profundidade de um episódio queer que, apesar de ter-se aberto nas margens da história do feminismo, tem comovido alguns de seus centros aparentemente mais próprios.

\section{Referências bibliográficas:}

AMORÓS, C. Tiempo de feminismo. Madrid: Ediciones Cátedra. 1997.

ANZALDÚA, G. Borderlands/La Frontera: The New Mestiza. San Francisco: Aunt Lute Books. 1987.

AUSTIN, J.L. How to Do Things with Words, The William James Lectures delivered at Harvard University in 1995. Oxford: Oxford at the Clarendon Press. 1962.

ASIAN WOMEN UNITED OF CALIFORNIA (Eds.). Making Waves: an Anthology of Writings by Asian American Women. Boston: Beacon Press. 1989.

BEAUVOIR, S. Le Deuxième sexe. París: Gallimard. 1949.

BULKIN, E., SMITH, B. (Eds.). Yours in Struggle: Three Feminist Perspectives on Antisemitism And Racism. Nueva York: Firebrand Books. 1984.

BUTLER, J. Gender Trouble: Feminism and Subversion of Identity. London and New York: Routledge. 2002.

CADY, E. La biblia de la mujer. Madrid: Cátedra, 1997 (The Women's Bible. Boston: Northeastern University Press. 1993).

CERECEDA, M. El origen de la mujer sujeto. Madrid: Tecnos. 1996.

CRENSHAW, K. "Demarginalizing the Intersection of Race and Sex: A Black Feminist Critique of Antidiscrimination Doctrine, Feminist Theory, and Antiracist Politics". Weisberg, Feminist Legal Theory: Foundations (pp. 17-29). Philadelphia: Temple University Press. 1993.

DE LA VIEJA. T. La mitad del mundo: Ética y crítica feminista. Salamanca: Ediciones Universidad de Salamanca. 2004.

DERRIDA J. Marges de la philosophie. Paris: Les Éditions de Minuit París. 1972.

EISENSTEIN, Z. "Hacia el desarrollo de una teoría del patriarcado feminista y el feminismo socialista. Eisenstein”. Patriarcado feminista y feminismo socialista. Madrid: Siglo XXI. 1980 .

ENGELS, F. The Origin of the Family, Private Property and the State. Chicago: Charles H. Kerr \& Co. 1909.

FIRESTONE, S. The Dialectic of Sex. Londres: The Women's Press, 1979. 
FOUCAULT, M. La voluntad de saber. Buenos Aires: Siglo XXI. 2005 (La volonté de savoir, Gallimard, París, 1976).

FRASER, N. Justice Interruptus: Critical Reflections on the "Postsocialist" Condition. New York: Routledge. 1995.

FRIEDAN, B. La mistica de la feminidad, Madrid: Júcar. 1974 (The Feminine Mystique. Nueva York: W.W. Norton and Company Inc., 1963).

GOLDMANN, E. Woman Suffrage. Emma Goldman's Anarchism and Other Essays. New York \& London: Mother Earth Publishing Association, p. 201-217, 1911.

GUERRA, M.J. ¿Subvertir o situar la identidad?, sopesando las estratégias feministas de Judith Butler y Sheila Benhabib. Daimon, Revista de Filosofía, p. 14, 143-154, 1997.

HARTMAN, H. Un matrimonio mal avenido: hacia una unión más progresiva entre marxismo y feminismo. Zona Abierta, 24, p. 85-114, 1980.

HOOKS., B. Ain't I a Woman: black women and feminism. Cambridge: South End Press, 1981.

HULL, G., BELL, P., SMITH, B. All the Women Are White, All the Black Are Men, But Some of Us Are Brave. Nueva York: The Feminist Press, 1982.

KELLY-GADOL, J. Early Feminist Theory and the 'Querelle des Femmes': 1400-1789. Signs, 8 (1), p. 4-28, 1982.

KELLY-GADOL, J. ¿Tuvieron un renacimiento las mujeres. Amelang, James, Nash, Historia y Género: las mujeres en la Edad Moderna y Contemporánea (pp. 93-125). Valencia: Dpto. De Historia del Arte. 1990 (Kelly-Gadol, Did Women Have a Renaissance?. Bridenthal, Koonz, Becoming Visible: Women in European History. Boston: Houghton Mifflin, p. 137163, 1977.

LAURETIS, T. Introduction, Queer Theory: Lesbian and Gay Sexualities. An Introduction. Differences: a Journal Of Feminist Cultural Studies, 3 (2), III-XVII. 1991.

LUGONES, M. Colonialidad y género. Tabula Rasa, 9, p. 73-101, 2008.

MILL, S. La sujeción de la mujer. Rossi, Ensayos sobre la igualdad sexual. Barcelona: Península, p. 155-288, 1973.

MILLET, K. Sexual Politics. New York: Doubleday and Co. 1970.

MORAGA, Ch., CASTILLO, A. Este puente mi espalda: Voces de mujeres tercermundistas en los Estados Unidos. San Francisco: ISM Press. 1988 (This bridge called my back: Writings by Radical Women of Color. New York: Kitchen Table: Women of Color Press. 1981).

OLIVEIRA, J. M. O rizoma 'género': cartografia de três genealogias, e-Cadernos CES, 15, p. 33-54, 2012.

PATEMAN, C. El contrato sexual. Barcelona y Iztapalapa: Anthropos. 1995. 
PÉREZ NAVARRO, P. Del texto al sexo. Judith Butler y la performatividad. Madrid: Egales, 2008 .

PÉREZ NAVARRO, P. Activismo y disidencias queer. Cuadernos del Ateneo, 26, p. 75-82, 2009.

PÉREZ NAVARRO, P. Parodias de la parodia en Martha Nussbaum y Celia Amorós. SoleyBeltrán, Sabsay, Judith Butler en disputa. Lecturas sobre la performatividad. Madrid: Egales, p. 27-58, 2012.

RICH, A. La heterosexualidad obligatoria y la existencia lesbiana. Navarro, Stimpson. Sexualidad, género y roles sexuales. México: Fondo de la Cultura Económica, p. 159-211, 1986. (Compulsory Heterosexuality and Lesbian Existence. Abel, The Signs Reader: Women, Gender and Scholarship. Chicago: University of Chicago Press, p. 139-168, 1983.

RORTY, R. Contigencia, ironía y solidaridad. Barcelona y Buenos Aires: Paidós. 1991.

RUBIN, G. Sexual Traffic. Differences: A Journal of Feminist Cultural Studies, 6 (3), 62-99, 1994.

RUBIN, G. Reflexionando sobre el sexo: notas para una teoría radical de la sexualidad. Vance, Placer y peligro: explorando la sexualidad femenina. Madrid: Talasa, p. 113-190, 1989.

ROWBOTHAM, S. La mujer ignorada por la historia. Madrid: Debate. 1980.

SCOTT, J. The evidence of experience. Critical Inquiry, 7 (4), p. 773-797, 1991.

SEDGWICK, E. Epistemology of the Closet. Berkeley: Berkeley University of California Press, 1990.

SMITH, B. Home Girls: A Black Fem Anthology. Nueva York: Kitchen Table: Women of Color Press, 1983.

SPELMAN, E. Inessential Woman: Problems of Exclusion in Feminist Thought. Boston: Beacon Press. 1988.

SPIVAK, G. Can the Subaltern Speak? Speculations on Widow-Sacrifice. Wedge, 8, p. 120$130,1985$.

TORTON, E. Nice Jewish Girls: A Lesbian Anthology. Watertown: Persephone Press, 1982.

TRISTÁN, F. La unión obrera. Barcelona: Debarris, 2006.

WITTIG, M. No se nace mujer. El pensamiento heterosexual y otros ensayos: Monique Wittig. Madrid: Egales, p. 31-45, 2006. (The Straight Mind and other essays. Boston: Beacon Press, 1992).

WOLLSTONECRAFT, M. Vindicación de los derechos de la mujer. Madrid: Istmo. 2005. 
Pablo Pérez Navarro: é pesquisador do Centro de Estudos Sociais (CES) da Universidade de Coimbra.

Artigo recebido para publicação em: setembro de 2018

Artigo aprovado para publicação em: novembro de 2018

\section{Como citar este artigo:}

Navarro, Pablo Pérez; História feminista, genealogías queer. In REVISTA TRANSVERSOS. "Dossiê: LGBTTQI. HISTÓRIAS, MEMÓRIAS E RESISTÊNCIAS". N 14, SET-DEZ, 2018, pp. 12-35 Disponível em $<$ https://www.epublicacoes.uerj.br/index.php/transversos/index>. $\quad$ ISSN 2179-7528. DOI:10.12957/transversos.2018.38653. 